\title{
REDUCING THE SEISMIC VULNERABILITY FOR RC BUILDINGS BY USING STEEL BRACING ELEMENTS
}

\author{
Naima EZZAKI - Ph.D Student, Technical University of Civil Engineering of Bucharest \\ Daniel STOICA -Assoc Prof. Eng. Ph.D,Technical University of Civil Engineering of Bucharest \\ Laurentiu RECE - Prof. Eng.Ph.D, Technical University of Civil Engineering of Bucharest \\ Arina MODREA- Assoc Prof, Ph.D University "Petru Maior" of Tg. Mures
}

\begin{abstract}
This article aims to highlight, through a comparative study, the efficiency of steel bracing systems used to reduce seismic vulnerabilities in existing buildings with reinforced concrete structures (reinforced concrete frames and reinforced concrete dual structures, general building structures including those used in transport infrastructure). In order to simplify the calculations, the analysis was reduced to the study of the behavior of resistance lines corresponding to four-, nine- and fifteen-level buildings with the same plane distribution. In order to obtain features similar to those of existing building elements, structures were initially loaded with seismic forces corresponding to code P13-63. The next step was to apply to previously dimensioned structures the seismic loads according to P100-3: 2008 in relation to P100-1: 2013, thus obtaining the deficiencies of the existing structures against the requirements of these norms. Correction of these strength and stiffness deficiencies was attempted by introducing $X$-shaped centric brace systems. The bracing systems used as consolidation methods are of three types: direct bracings stuck in the reinforced concrete frames and bracings of the indirect type, made of internal and external bracing steel frames. Structural calculations were made in the linear elastic field using the ETABS program.
\end{abstract}

Keywords: P13-63; vulnerability; earthquake; bracing

\section{INTRODUCTION}

At present the specialty literature includes many theoretical studies and experimental tests regarding systems for the strengthening of structural elements or sub-structures. Lab tests are valuable for studying intervention techniques; nevertheless, they have certain limitations due to the difficulty of correctly reproducing the support conditions, of quantifying the effect of using a small-scale model, as well as of including the deficiencies of existing buildings (construction tolerances, operations drawbacks, corrosion of the reinforcement bars and concrete decay). Because of these difficulties, the opportunity of leading tests presuming the collapse of existing buildings is viewed as a unique chance to improve the knowledge regarding consolidation methods analysis and design; this opportunity emerged during the ILVA-IDEM project that took place in Bagnoli, Naples, Italy between 2000 and 2005. [1]. 


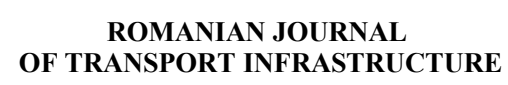

Naima EZZAKI, Daniel STOICA, Laurentiu RECE, Arina MODREA

Reducing the seismic vulnerability for rc buildings by using steel bracing elements

At international level, apart from research results and tests, there is also a clear legislation with reference to the consolidation of existing buildings, as follows:

- FEMA 273 - NEHRP Guidelines for the seismic rehabilitation of buildings;

- The New Zealand Draft Code NZDC - Assessment and improvement of structural performance regarding the seismic risk of buildings (the original title of code);

- SERC Report - Drawing up of the guidelines for stress and performance assessment in the case of existing buildings, and recommendations regarding the consolidation projects for ensuring buildings' resistance to earthquakes;

- UNIDO Vol. 4 - Assessment of the post-earthquake building response and deterioration under seismic conditions;

- Eurocode 8 - Design provisions for resistance to earthquake. Parts 1-4: General regulations for the consolidation and repair of buildings.

In Romania Eurocode 8 is implemented through P100-3 Regulation / Assessment and design code for consolidation works on existing buildings which are highly vulnerable to earthquakes.

The consolidation of structures in view of potential seismic events can be characterized by several key steps. The first step is the assessment of basic characteristics and of the existing building's resistance capacity to seismic events. Then the decision is taken regarding the performance objectives and the resulting seismic hazard level.

A thorough assessment of the existing buildings must be made in order to determine the nature and size of deficiencies which may cause an inappropriate behavior to seismic events. This assessment will also help establish if any local or global changes are needed. The consolidation success depends on the choice of the consolidation technique, depending on the material and structural system of the existing building.

Further on, the design and analysis need a high degree of experience and finesse, similar to that which is needed for the erection of a new building. All documentation regarding the structural consolidation includes general diagrams for rehabilitation, but they do not offer instructions for the common consolidation techniques such as jacketing, insertion of more shearing walls and bracing systems. 


\section{ABOUT THE LOCAL CHANGE OF COMPONENTS}

Several components (such as the beams, posts, joints, walls, diaphragms, etc.) in an existing building may not have the adequate resistance or deformation capacity, although the building as a whole has a substantial resistance and rigidity. For these components local changes can be made, while maintaining the basic configuration of the resistance to horizontal forces. Local changes taken into consideration are the joints between elements, their individual resistance and deformation capacity.

FEMA 273 and NZDC state that elements can resist to significant deformations without breaking if their deformation capacity or ductility is improved, without implicitly increasing their resistance.

For instance, concrete jacket covering of a reinforced concrete column, in order to improve its confining, ensures its ability to deform without exfoliation or degradation of reinforcing joints. According to FEMA 273, the cross section of a structural element may be reduced in order to enhance its flexibility and response to deformation.

According to Eurocode 8, local or general changes may be made on affected structural elements (repairs or consolidation works) taking into account their rigidity, density and ductility. Also, extremely damaged elements should be replaced. The structural consolidation, as defined in the UNIDO Manual, also implies the change of existing structural elements, so that their resistance and ductility levels are improved.

Therefore, the respective characteristics of the structure (column concrete jacket covering) are influenced although the structural diagram is not changed.

\section{CONSOLIDATION WITH STEELBRACING SYSTEMS}

Consolidation is necessary because many buildings erected in areas with a high seismic hazard do not have the necessary capacity to withstand earthquake loads. Although these buildings were designed and built according to the provisions of existing norms at the time, the systems of taking over horizontal loads are inappropriate for the more rigorous and more complex requirements of the norms we apply today.

The non-ductile behavior of existing buildings with reinforced concrete frameworks is due to an inadequate cross reinforcement in columns, beams and joints, to the slide of the lower joint reinforcement as well as to the insufficient column confining.

Some of the most commonly used methods of reinforcement for seismic activities are the following: filler walls, adding short "wing" walls near the columns, adding metallic bracing systems, column casing. The first three methods are used in 


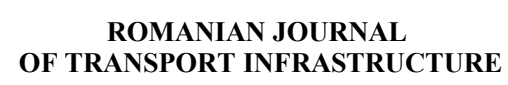

Naima EZZAKI, Daniel STOICA, Laurentiu RECE, Arina MODREA

Reducing the seismic vulnerability for rc buildings by using steel bracing elements

order to increase the resistance capacity, the fourth being used more for enhancing the ductility of the structure.

Following the Miyagiken-Oki earthquake of 1978 in Japan, a number of 157 buildings were consolidated. For $45 \%$ of them the filler walls method was used; the side "wing" walls represented the solution for $15 \%$ of the buildings, while for $1 \%$ of them metallic bracing systems attachment was preferred. Sugano, a Japanese scientist tested various consolidation techniques on ten one-level frames having an opening, using a 1:3 small-scale model. The nine types of resistance improvement solutions, along with the initial reinforced concrete frame, were made of the following elements: two frames with monolith concrete walls of different thickness, one concrete wall, two frames with filler walls having different attachment systems, one frame with a thin wall whose thickness was increased, one frame with a steel panel mounted on the beams with screws, a frame with metallic bracings working under compression, and another with bracings working under stretching forces.

Some of these frames are presented in Figure 1 along with their respective cracking models and hysteresis curves. The diagram for the simple frame is at a different scale than the other diagrams.[3]

The steel bracings proved to be one of the best solutions for taking over the horizontal loads. These are efficient because the diagonals work at axial efforts and, therefore, they need small sections in order to ensure rigidity and safe bracing capacity in taking over the seismic forces.

Potential metallic bracing models include X-shaped bracings, K-shaped bracings, diamond-shaped or eccentric ones. Bracings may be designed to resist to the entire horizontal load or just part of it. An important issue is the effort transfer from the reinforced concrete elements to the metallic bracings. Vertical and horizontal metallic elements attached to beams and reinforced concrete columns may perform this transfer.

As a rule, two types of bracing systems are considered: external and internal ones. For the external bracing system, the metallic elements are attached all around the outside of the building, or locally, to a reinforced concrete frame. The inadequacies of this type of system reside in architectural issues and in the difficulty of connecting metallic elements to reinforced concrete ones. Bush, Jones, Jirsa, studied the cyclic loading on external system models using small-scale models at two thirds of the actual size, confirming the efficiency of these systems for the consolidation of existing reinforced concrete frames. Badoux and Jirsa made a numerical research of the external bracing system and they recommend the use of diagonal cables, to avoid the buckling of the bracing frame and increase beams ductility. 
ROMANIAN JOURNAL

OF TRANSPORT INFRASTRUCTURE

Naima EZZAKI, Daniel STOICA, Laurentiu RECE, Arina MODREA Reducing the seismic vulnerability for rc buildings by using steel bracing elements
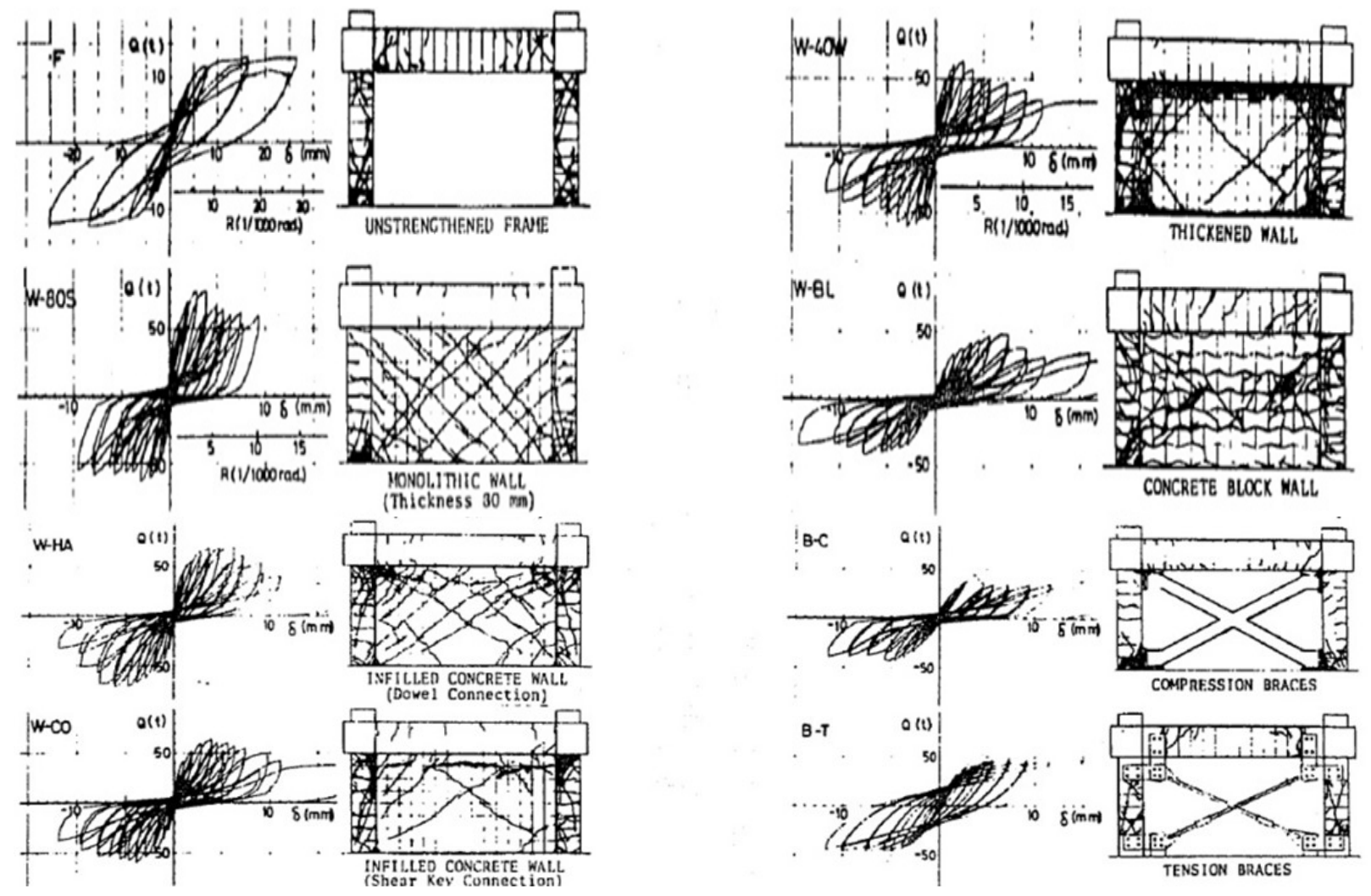

Figure 1. Cracking models and hysteresis curves of Sogano's test [3]

\section{PRESENTATION OF THE WORKING CASE STUDIES METHODOLOGY (AUTHORS CONTRIBUTION)}

The structural systems of existing buildings referred to in this study have seven openings, seven bays of $6 \mathrm{~m}$ each and a plane distribution of elements (beams, columns and reinforced concrete walls) according to the arrangement in Figure 2. The height of each level is $3 \mathrm{~m}$. The computer program used was ETABS, using level 2 and 3 methodologies.

The resistance line corresponding to axis F, presented in elevation in Figure 3., was our choice for this study.

In order to rebuild the joints of the resistance lines as if they were never separated from the building, they were loaded, from the point of view of gravity, with specific loads corresponding to the adjacent bays, according to the bisector rule, as shown in Figure 4. Also, in the ETABS program the joints between columns and beams were blocked to prevent movements in the direction y (perpendicular on the elevation) and twists around axes $\mathrm{x}$ and $\mathrm{z}$. 
ROMANIAN JOURNAL

OF TRANSPORT INFRASTRUCTURE

Naima EZZAKI, Daniel STOICA, Laurentiu RECE, Arina MODREA

Reducing the seismic vulnerability for rc buildings by using steel bracing elements

The placement of the resistance line function of the axes is shown in Figure 5. At the same time, in order to maintain the characteristics of an existing building, the materials used were concrete classes C12/15, C16/20 and PC52 steel.
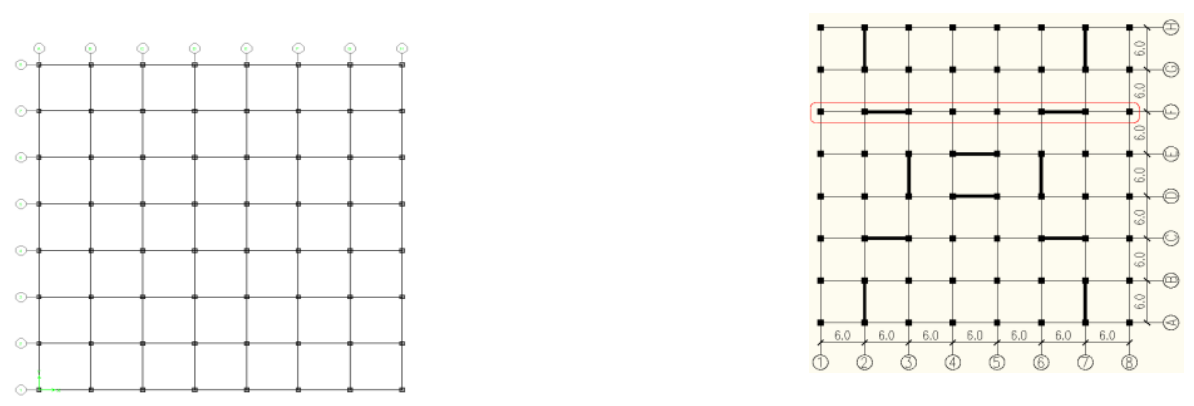

Figure 2 Plane distribution of structural elements

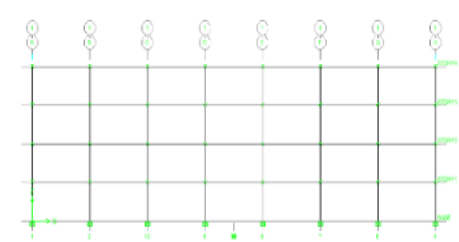

4-level building

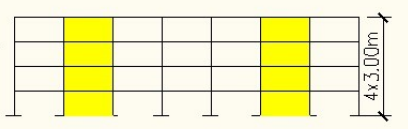

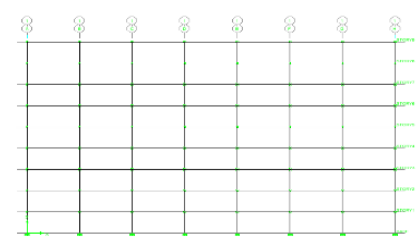

9-level building

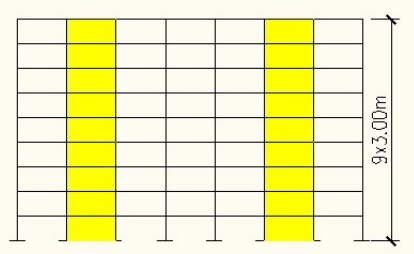

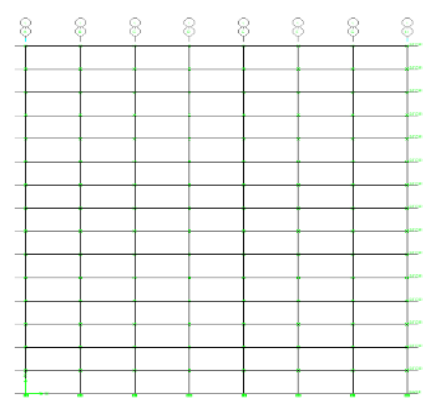

15-level building

Figure 3 Elevation of $\mathrm{F}$ axis for the structure with 4,9 and 15 levels 
ROMANIAN JOURNAL

OF TRANSPORT INFRASTRUCTURE

Naima EZZAKI, Daniel STOICA, Laurentiu RECE, Arina MODREA

Reducing the seismic vulnerability for rc buildings by using steel bracing elements

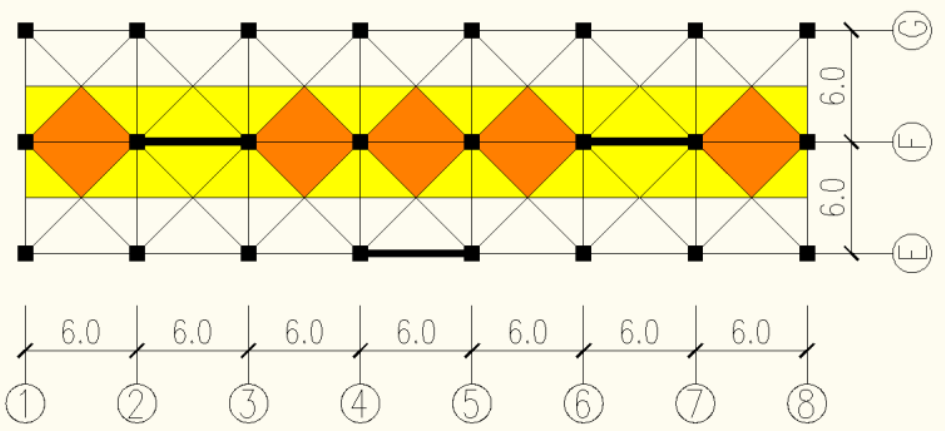

Figure 4. Plane view of gravitational loads incidental to resistance lines elements

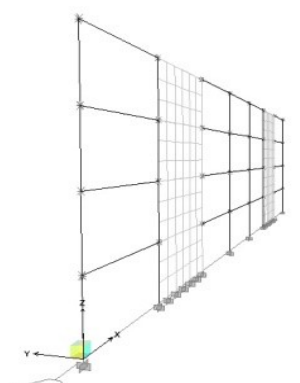

Figure 5. Resistance line for the 4-level structure, 3D view

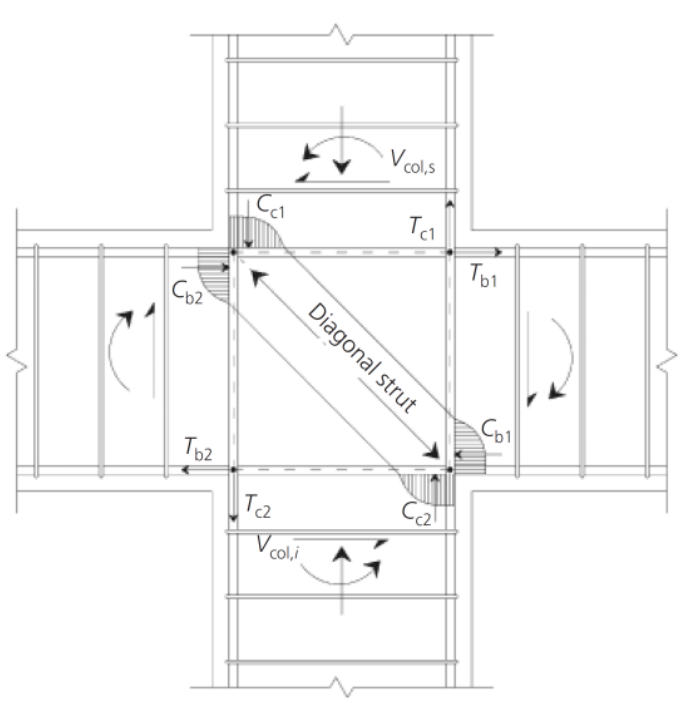

a

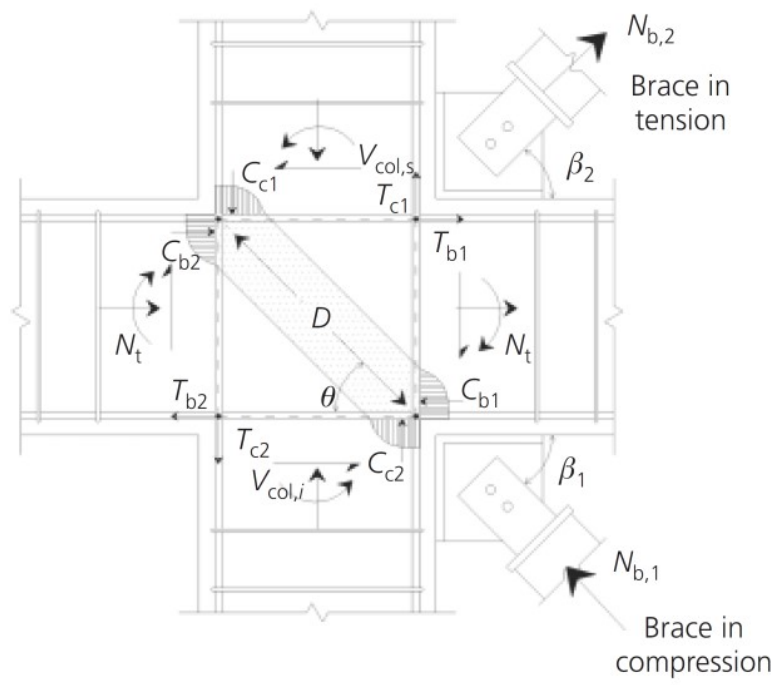

b 
ROMANIAN JOURNAL

OF TRANSPORT INFRASTRUCTURE

Naima EZZAKI, Daniel STOICA, Laurentiu RECE, Arina MODREA Reducing the seismic vulnerability for rc buildings by using steel bracing elements
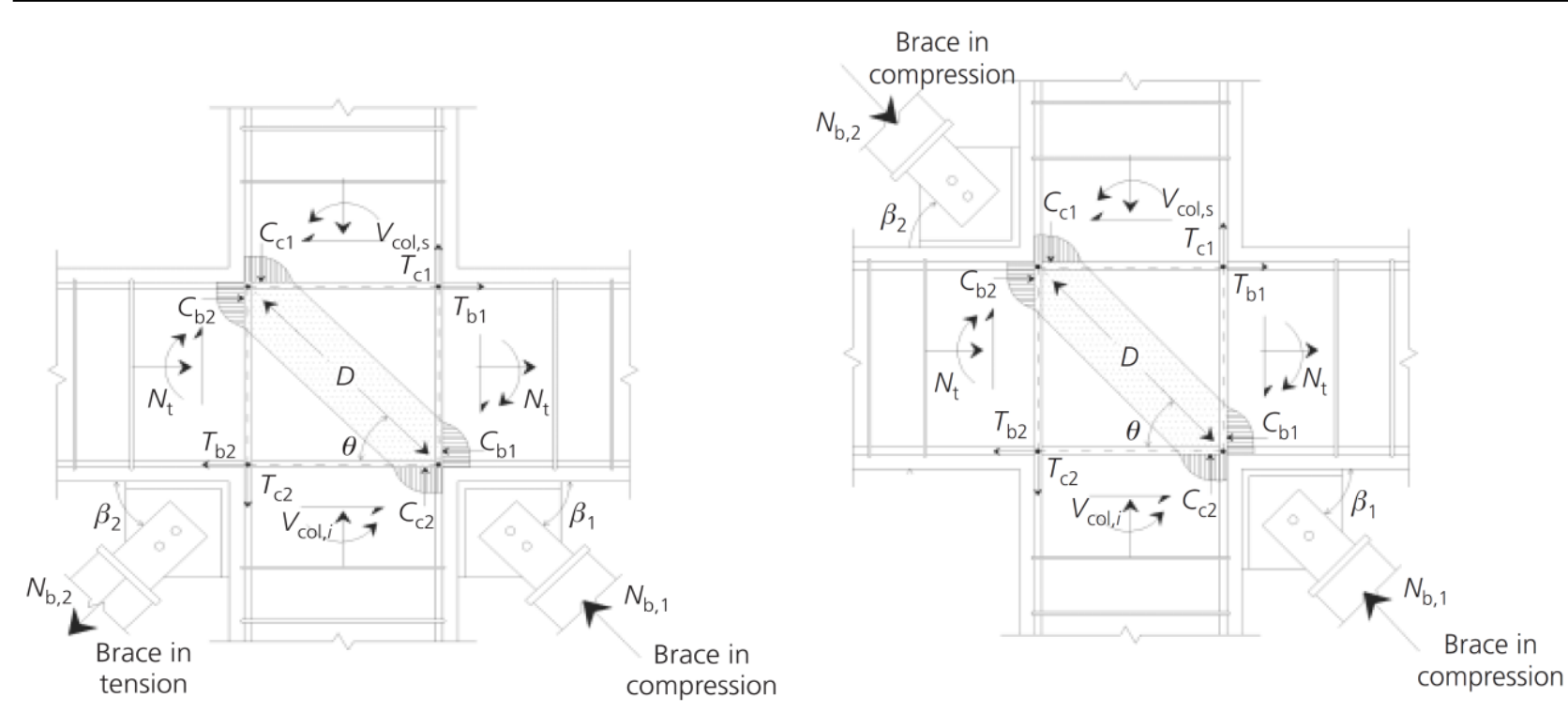

c

d

Figure 6 - Equilibrium for an interior joint ( $a$ - initial; b, c, d - with braces)

The presence of steel braces strongly affects the force demand on RC beamcolumn joints under seismic actions. As a matter of fact, joints in $\mathrm{RC}$ frames are subjected to relevant shear actions induced by both the shear force in the columns and axial actions transferred by either the compressed zone or the yielded tensile bars on beams. Basically, the horizontal shear force across the joint region can be evaluated by the equilibrium of the bottom part of the joint shown in Figure 6 as follows :

$$
\mathrm{V}_{\mathrm{jh}, \mathrm{E}}=\mathrm{C}_{\mathrm{b} 1}+\mathrm{T}_{\mathrm{b} 2}-\mathrm{V}_{\mathrm{col}, \mathrm{I}}
$$

in which $\mathrm{C}_{\mathrm{b} 1}$ and $\mathrm{T}_{\mathrm{b} 2}$ are respectively the compressive stress in the beam concrete and the tensile stress in the bottom beam reinforcement (assuming, as a reference, an earthquake load from the left to the right) and $\mathrm{V}_{\text {col, }}$ is the shear force of the bottom column.

However, by equilibrium of the internal force applied on a transverse beam section in bending, the identity $\mathrm{C}_{\mathrm{b} 1}=\mathrm{T}_{\mathrm{b} 1}$ can be easily demonstrated. Furthermore, the development of plastic hinges in the beams, immediately connected to the column faces, is expected under seismic actions. Consequently, the ultimate strength is supposed to be achieved in the beam longitudinal steel bars which are in tension. Thus, the following expression can be easily derived for determining $\mathrm{V}_{\mathrm{jh}, \mathrm{E}}$ if an elastic-perfectly plastic behavior is supposed for steel

$$
\mathrm{V}_{\mathrm{jh}, \mathrm{E}}=\left(\mathrm{A}_{\text {sup }}+\mathrm{A}_{\text {inf }}\right) \mathrm{f}_{\mathrm{sm}}=\mathrm{V}_{\mathrm{col}, \mathrm{I}}
$$

where $A_{\text {sup }}$ and $A_{\text {inf }}$ are the amount of steel reinforcement at the top and the bottom of the beam passing the joint, respectively and $\mathrm{f}_{\mathrm{sm}}$ is the yield stress of the steel. 


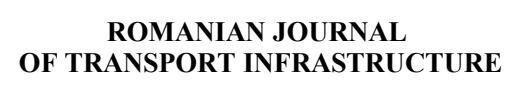

Naima EZZAKI, Daniel STOICA, Laurentiu RECE, Arina MODREA

Reducing the seismic vulnerability for rc buildings by using steel bracing elements

However, the joints of the RC frames retrofitted by steel bracings are subjected to significant tension or compression forces transferred by the steel diagonals. These actions can be equilibrated through an interior strut-and-tie mechanism. In Figure 5 the configuration of a $\mathrm{RC}$ beam-to-column joint with a steel diagonal connected to realize a concentric X-bracing system is depicted for the three possible retrofitting solutions considered in this study. Thus, the equilibrium of Equation 1 should be rewritten by considering the axial forces of braces $\left(\mathrm{N}_{\mathrm{b}, 1}\right.$ and $\left.\mathrm{N}_{\mathrm{b}, 2}\right)$, and the shear force transferred to beam-to-column joint in the cases of patterns 1 and 3 which can then be evaluated as follows

$$
\mathrm{V}_{\mathrm{jh}, \mathrm{E}}=\left(\mathrm{A}_{\text {sup }}+\mathrm{A}_{\text {inf }}\right) \mathrm{f}_{\mathrm{ys}}-\mathrm{V}_{\mathrm{col}, \mathrm{i}}+\mathrm{N}_{\mathrm{b}, 1} \cos \beta_{1}
$$

Otherwise, for steel diagonals arranged as in pattern 2, the equilibrium of the bottom part of the joint under consideration also includes the axial force of the bracing in tension

$$
\mathrm{V}_{\mathrm{jh}, \mathrm{E}}=\left(\mathrm{A}_{\text {sup }}+\mathrm{A}_{\mathrm{inf}}\right) \mathrm{f}_{\mathrm{ys}}-\mathrm{V}_{\mathrm{col}, \mathrm{i}}+\mathrm{N}_{\mathrm{b}, 1} \cos \beta_{1}+\mathrm{N}_{\mathrm{b}, 2} \cos \beta_{2}
$$

As expected, the steel bracing configuration results in the highest shear force transferred to beam-to-column joints. However, all retrofitting solutions under consideration are characterized by a significant increase in shear force demand, although the solution corresponding to the so-called study cases results in the lowest increase, and its superior performance also under this standpoint is then confirmed.

\section{CONCLUSIONS REGARDING THE USE OF STEEL BRACING SYSTEMS FOR BUILDINGS WITH REINFORCED CONCRETE STRUCTURE (AFTER THE THEORETICAL CONSIDERATION AND NUMERICAL RESEARCH FOR CASE STUDIES)}

When steel bracing systems are used in order to reduce the seismic vulnerability of existing buildings having a reinforced concrete structure it is important to analyze the existing structure and to find its weak points. The building may have rigidity and/or resistance flaws. Different bracing or bracing placement systems in elevation give different results regarding the improvement of resistance and rigidity; that is why bracings could either neutralize the building faults or emphasize these faults.

For structures with reinforced concrete frames, a significant reduction of relative level displacements resulted from the use of steel bracings (table 1 and figure 7): 
Table 1

\begin{tabular}{|c|c|c|c|c|c|c|c|c|}
\hline \multirow{2}{*}{ Levels } & \multicolumn{9}{|c|}{$\%$} \\
\cline { 2 - 9 } & $\mathbf{1}^{\text {st }}$ case & $\begin{array}{c}\mathbf{2}^{\text {nd }} \\
\text { case }\end{array}$ & $\begin{array}{c}\mathbf{3}^{\text {rd }} \\
\text { case }\end{array}$ & $\mathbf{4}^{\text {th }}$ case & $\mathbf{5}^{\text {th }}$ case & $\mathbf{6}^{\text {th }}$ case & $\mathbf{7}^{\text {th }}$ case & $\mathbf{8}^{\text {th }}$ case \\
\hline $\mathbf{4}$ & 76.97 & 62.83 & 78.28 & 96.24 & 88.77 & 98.09 & 53.02 & 94.93 \\
\hline $\mathbf{9}$ & 35.77 & 20.09 & 37.57 & 80.48 & 64.63 & 66.32 & 9.59 & - \\
\hline $\mathbf{1 5}$ & 0.14 & 3.53 & 13.59 & 66.71 & 58.15 & 79.66 & 26.02 & - \\
\hline
\end{tabular}

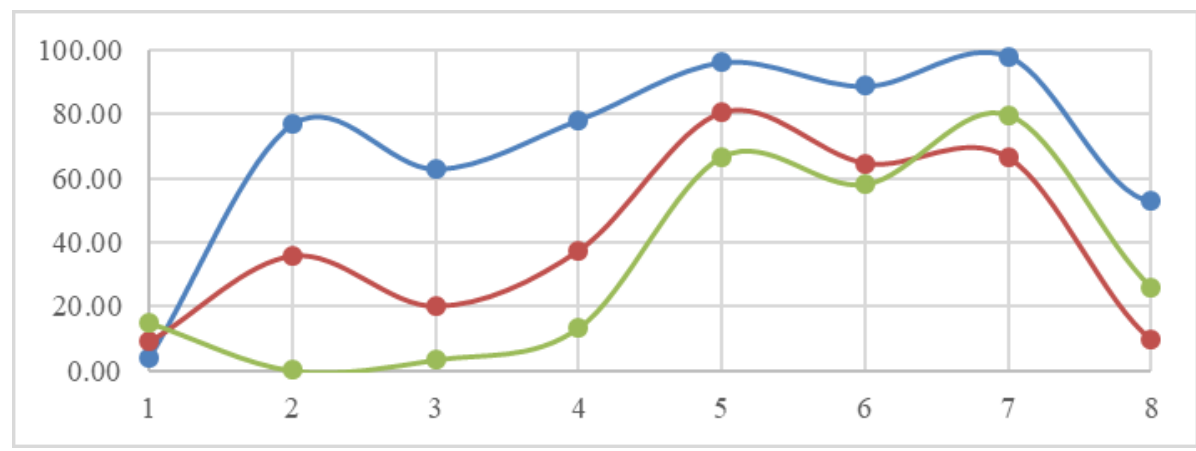

Figure 7 - Relative displacements reduction

As for stresses, it can be noted that the steel bracing systems reduce maximum bending moments and maximum shearing forces in the columns. This results in an increase of the axial compression force. Taking into account the above information, for small and medium height buildings designed with a reinforced concrete structure (up to 15 levels) the most beneficial way of mounting bracings in frame holes is the one in case 6.

As for buildings with a dual reinforced concrete structure, they had problems regarding their resistance capacity, while the relative level movements have values under the admissible limits.

This is due to the walls which ensure a higher strength to the resistance lines. On the other hand, because of the rigidity, walls behave as stress concentrators, by emphasizing the lack of resistance shown by the component elements of the resistance line.

Comparisons were made in two different ways. On the one hand, the results from bracing systems "a", "b" and "c" were compared; on the other hand, the bracing systems assembly models 1 to 8 were compared.

The rigidity of the resistance lines can be characterized by their own basic periods and by relative level movements. The bracing system "b" had the best results in reducing the periods and relative level movements. Systems "a" and "c" had similar effects, with small differences: system "a" reduced individual periods more than system "c", while system "c" reduced the relative level movements more. 
As for the bending moments and shearing forces in beams and columns, systems "a" and "c" were the most efficient ones in reducing them. System "b" had a significantly smaller effect on stress reduction, and, in certain cases, the resulting stresses were higher than those of the non-consolidated structure. The values of the shearing forces were especially higher than the initial ones. To conclude, systems type "a" and "c" may be used for a wider range of purposes, because they determine the improvement of both resistance and rigidity, while the use of a type "b" system requires careful attention because, in spite of its excellent results with rigidity, it determines a stress increase in the reinforced concrete elements.

A comparison of all the models of bracing systems in elevation showed that model 8 was the most efficient one, both from the point of view of stress reduction and in improving the rigidity level.

This leads to the conclusion that the use of as many bracing frames as possible, randomly placed in all the openings of the resistance line, gives very good results irrespective of the flaw in the existing structure. Models 1 and 6 had good results in rigidity improvement, while models 2,3 and 4 had good results for stress reduction.

Therefore, a linear placement of the bracing frames, both in the central openings and in the lateral ones is efficient for rigidity purposes, while a random placement of the bracing frames is more appropriate for stress reduction. The presence of bracing frames is important for reducing stresses in all the openings, as proved by the fact that model 4 had worse results than models 2 and 3 .

Models 5 and 7 had the worst results in improving structure resistance and rigidity. They use the least number of bracing frames and are mounted in line in each opening; as a result, their influence on the resistance line is weak or nil. A comparison of the two showed that model 7 had better results regarding the rigidity and resistance, due to the fact that the bracing frames were placed near the wall, with better rigidity results if bracings are not fit on the walls. Also, the shearing forces in the columns were higher in the case of model 7.

The performance of bracing systems and models analyzed with the purpose of reducing stresses down to values under beams, columns and joints capacity shows that complying with the joints' capacity was a real challenge.

For the resistance lines with four levels, the compressed concrete diagonal of the joint was confirmed in the case of models 3, 4, 5, 6 and 8 for all types of bracing systems; note, however, that in the case of system " $b$ " the shearing forces in the columns reached higher values than their shearing capacity. The joints' resistance was the only deficiency of the 4-level resistance lines. As a rule, the validation of joint safety clips was not satisfactory, irrespective of the number of levels, because the number of safety clips in the joints was insufficient. 
In some cases, this validation was satisfactory because the resistance requirement depends on the axial force in the columns. In the case of 9-level resistance lines the validation of the compressed diagonal in the joint was satisfactory only for the combination of model 8 with the system "c". Resistance lines consolidated with systems "a" and "c" reduced the stresses in the columns and beams below resistance values, except for the maximum shearing force in the columns.

For system "c", models 5 and 7 and the maximum bending moments in the beams exceeded the bending capacity. In the case of system " $b$ " the purpose was met only for the bending moments in the columns and beams, for some of the models. In the case of model 7 the compression capacity of the columns near walls was exceeded. The compression capacity of the columns was exceeded by the bulbcolumns of the resistance lines by 15 levels for models $1,5,6$ and 7 .

The use of models 2, 3, 4 and 8 resulted in a reduction of bending moments and shearing forces under the values of the related resistances. In general, combined consolidation procedures, such as bracing and RC jacket covering, filling walls or shearing walls must be considered in the case of structures with a great height regime.

Finally, like all the retrofitting methods, using the steel bracing elements is not infallible. This is the idea for a specialist in this field, that considering different types of building structures, shapes or rise, to choose "surgically" that method to provide the best responses.

SI units were used for all the studies (length - meters; force $-\mathrm{kN}$; vibration periods - seconds).

\section{REFERENCES}

[1] Bush TD, Jones EA, Jirsa JO. Behavior of RC frame strengthened using structural-steel bracing. J Struct Eng-ASCE 1991;117(4):1115-26

[2] Badoux M, Jirsa JO. Steel bracing of RC frames for seismic retrofitting. J Struct Eng-ASCE 1990;116(1):55-74

[3] Mario D'Aniello - Steel Dissipative Bracing Systems for Seismic Retro fitting of Existing Structures: Theory and Testing

[4] Dr. Durgesh C Rai, Review of Documents on Seismic Strengthening of Existing Buildings Department of Civil Engineering Indian Institute of Technology Kanpur

[5] Elizabeth A.Jones, James O. Jirsa - Seismic Strengthening of a reinforced concrete frame using structural steel bracing

[6] M.A. Youssef, H. Ghaffarzadeh, M. Nehdi - Seismic performance of $R C$ frames with concentric internal steel bracing 
ROMANIAN JOURNAL

OF TRANSPORT INFRASTRUCTURE

Naima EZZAKI, Daniel STOICA, Laurentiu RECE, Arina MODREA

Reducing the seismic vulnerability for rc buildings by using steel bracing elements

[7] Viswanath K.G, Prakash K.B., Anant Desai-Seismic Analysis of Steel Braced Reinforced Concrete Frames

[8] Marc Eric Badoux - Seismic retrofitting of seismic reinforced concrete structures with steel bracing systems

[9] Ciro Faella, Carmine Lima, Enzo Martinelli, Roberto Realfonzo - Steel bracing configurations for seismic retrofitting of a reinforced concrete frame - Structures and Buildings Volume 167, Issue SB1 - ICE proceedings, 2014

[10] http://www.nexus.globalquake model.org/gem-building-taxonomy/overview/glossary/bracedframe-lfbr

[11] P100-3:2007 Code for evaluation and design of consolidation works on existing, seismically vulnerable buildings

[12] P100-1:2006 Design provisions for buildings

[13] SR EN 1993-1-1 Eurocod 3 Design of steel structures. Part 1-1: General rules and rules for buildings 